\title{
Participation Dynamics: The More, the Merrier
}

\section{Riccardo DiCecio}

$\mathrm{T}$ he labor force participation rate (LFPR) is the ratio of the labor force, employed and unemployed, to the working-age population. Together with the unemployment rate and labor productivity, the LFPR is one of the determinants of per capita GDP: A larger labor force will produce more output. LFPRs vary by age and gender. The demographic structure of a country's population will influence its level of output; policymakers must understand how their decisions influence labor force participation.

The table reports LFPRs for the United States, Europe, and Japan for 1994 and 2005 and breaks down those rates by age and gender groups. The differences between U.S. labor force participation and those of Europe and Japan shrank over the past decade: All three areas now display participation rates above 70 percent. The gap between male and female participation rates narrowed, especially in Europe, but at a slower rate than in previous decades. U.S. female labor participation stopped growing for the first time since the post-WWII period, but the male/female gap actually narrowed because of a slight reduction in male participation. Differences in childcare subsidies and the tax treatment of second incomes influence crosscountry differences and changes in the participation rates of women. ${ }^{1}$ The United States is unusual in that it has high female participation but few subsidies to support that participation.

Youth participation rates kept shrinking between 1994 and 2005, although at a slower rate than in previous decades. This reflects the tendency of young people to remain in school longer. The declining youth LFPR reduces total participation but might indirectly raise productivity if young people become better educated and trained before joining the labor force.

The increase in older workers' participation is a new development. Increased participation rates for older women outpaced the decline in participation rates for older men, resulting in an overall increase for older workers. International differences in older male participation do not appear to be related to participation of prime-age and young men. However, countries with low overall female participation rates also have low participation rates for older women, suggesting that many of the same factors drive participation for both younger and older women.

The aging of the population in developed countries means that the participation rates of older workers will become more important in the future. ${ }^{2}$ The share of the population aged 65 and over is projected to be 20 percent for the United States and more than 35 percent for Italy, Spain, and Japan by 2050. If the participation rates by age and gender groups were to remain at the 2005 values, the overall LFPR would be sharply lower, as would per capita GDP. ${ }^{3}$ For Japan, France, and Germany, the aging of the population could reduce the annual growth rate of per capita GDP by 0.2 to 0.3 percentage points over the next half century. The effect would be even more dramatic for countries that age faster and have lower participation rates for older workers, such as Greece, Italy, and Spain. An increase in the participation rates of older workers can mitigate this effect. Hence, designing policies that encourage older workers to remain in the labor force becomes crucial.

${ }^{1}$ Jaumotte, F. "Labor Force Participation of Women: Empirical Evidence on the Role of Policy and Other Determinants in OECD Countries." OECD Economic Studies, 2003, No. 37, pp. 51-108.

2OECD. Ageing and Employment Policies: Live Longer, Work Longer. Paris: 2006.

${ }^{3}$ Oliveira Martins, J.; Gonand, F.; Antolin, P.; de la Maisonneuve, C. and Yoo, K.

"The Impact of Ageing on Demand, Factor Markets and Growth." Working Paper No. 420, OECD Economics Department, 2005.

\section{Labor Force Participation Rates (percent)}

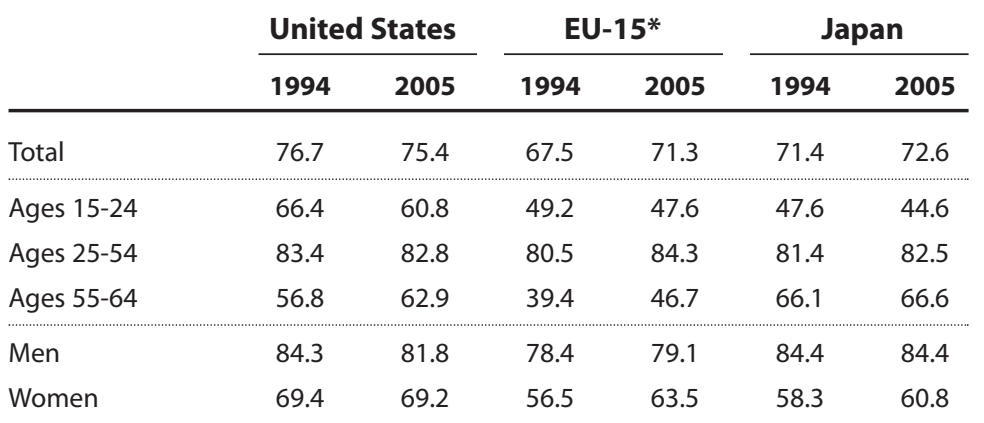

SOURCE: Organisation for Economic Co-operation and Development. OECD Employment Outlook-2006 Edition: Boosting Jobs and Incomes. Paris: 2006.

*Euro area countries (Austria, Belgium, Finland, France, Germany, Greece, Ireland, Italy, Luxembourg, the Netherlands, Portugal, and Spain) plus the United Kingdom, Sweden, and Denmark. 